\title{
Engraving and Cutting of Plastic Material Parts Using Low-Power Lasers
}

\author{
ANCA BUCURESTEANU ${ }^{1}$, ADRIAN MOTOMANCEA ${ }^{2 *}$, DAN PRODAN ${ }^{1}$, \\ ALINA OVANISOF ${ }^{2}$ \\ ${ }^{1}$ Politehnica University of Bucharest, Industrial Engineering and Robotics Department, 313 Splaiul Independentei, 060042, \\ Bucharest, Romania \\ ${ }^{2}$ Politehnica University of Bucharest, Mechanics Department, 313 Splaiul Independentei, 060042, Bucharest, Romania
}

\begin{abstract}
This paper presents some of the authors' theoretical and experimental research related to the use of low-power lasers (diode laser) for the engraving, photoengraving and cutting of the parts made of plastics. There shall be presented the research carried out using a small machine, covering a net area of 150x150mm ${ }^{2}$. Small-sized companies or the persons having such pursuits can afford this type of machines. The authors also put forward several solutions to improve the performance of such machines by introducing at least one new axis of the " $Z$ " or " $A$ " type.
\end{abstract}

Keywords: Engraving and cutting plastics, low-power laser, laser photoengraving

\section{Introduction}

Using laser technology, engraving, photoengraving and cutting can be performed under high precision and speed conditions. Various materials, metallic or non-metallic, can be processed. Due to the focus accuracy and to the accuracy of the advance systems, small areas and contours can be processed, which cannot be executed by using other procedures.

Engraving represents the procedure to print materials by transposing certain drawings or texts.

The engraving outcomes are figures and texts usually transposed on flat surfaces of constant widths and depths. The laser allows a higher degree of detail and finished products.

Photoengraving is the procedure to carry out surface engraving in the form of three-dimension white/black images (in plane but on variable depth). The quality and appearance of the engraving depend on both the model image resolution and contrast and on the behavior of the support material.

Laser cutting implies the full cutting of some contours of the plate-like material. The parts thus obtained are characterized by high dimensional accuracy and good quality of the areas resulted after cutting. The areas are completely burr-free.

The thickness of the cutting laser radius is comparable with $0.2 \mathrm{~mm}$, depending on the selected material, materializing as a spot of light on the semi-finished product.

Using industrial lasers, it is very easy to engrave, photoengrave and cut plastic plates whose width may even exceed $10 \mathrm{~mm}$.

Low-power lasers are lasers that do not use consumables and whose processing possibilities are low.

\section{Materials and methods}

The machine used is presented in Figure 1 [1], along with its cinematic scheme.

Crossbar 2 can move on the fixed structure 2, which represents the movement on the " $X$ " axis. Carrier 9 moves on this crossbar, which allows work on the second " $X$ " axis [2,3]. The crossbar movement is performed by toothed belt 3, driven by engine 4(EMY) using wheel 5. Engine 6(EMX) drives toothed belt 8 using belt pulley 7 [2,3]. The belt is tensioned using wheel 11. Laser diode 10 on carrier 9 emits, as per the figure, on direction " $Z$ ", perpendicular on the plan of the " $X$ " and "Y" axes.

\footnotetext{
$\overline{\text { *email:motom@deltainfo.ro }}$
} 

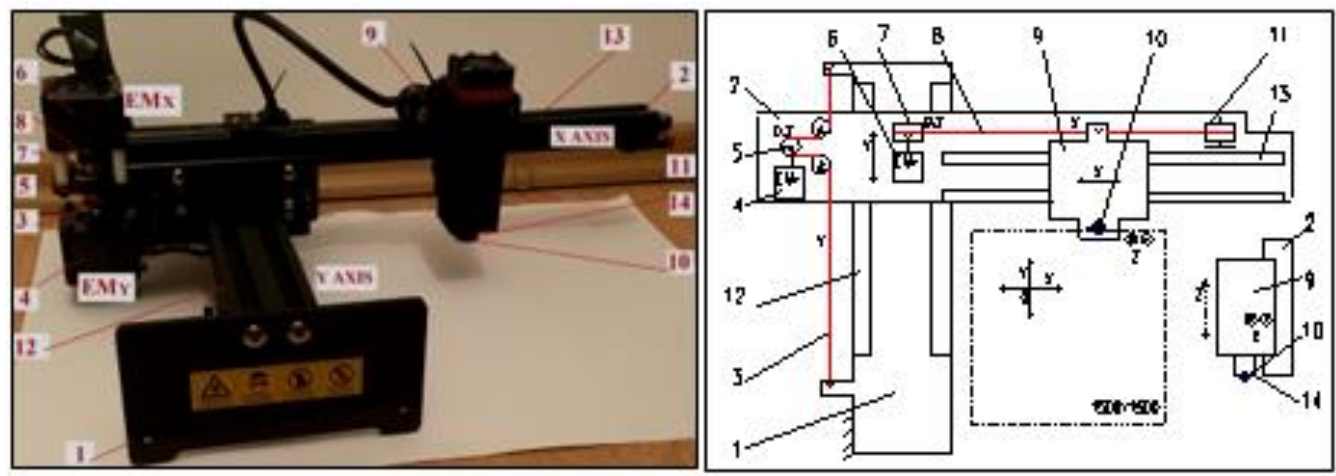

Figure 1. The engraving, photoengraving and laser cutting machine and its cinematic scheme

These two axes are perpendicular on each other the same as the corresponding slide ways 12 and 13 [4]. The focus of the laser beam is carried out with the adjustment element 14.

The working area of the machine is $150 \times 150 \mathrm{~mm}^{2}$

Of the characteristics of this machine we mention [1]:

Laser Power: 20W (laser input: 12V 2A);

Laser Wave Length: 450nm;

Image Format: .nc .dxf .bmp .jpg .png etc.;

Image Size: $2000 * 2000$ pixels / 0.075mm point distance;

Support System: Win7 / Win8 / XP / Win10 / Macbook, Android APP (NEJE scanner).

The installation of the machine is easy, as the following four steps are enough;

1-download the specific software;

2-power supply;

3-connect the laptop or computer on the USB port;

4-focus adjustment.

Figure 2 shows the adjustment modality and the laser beam working area.

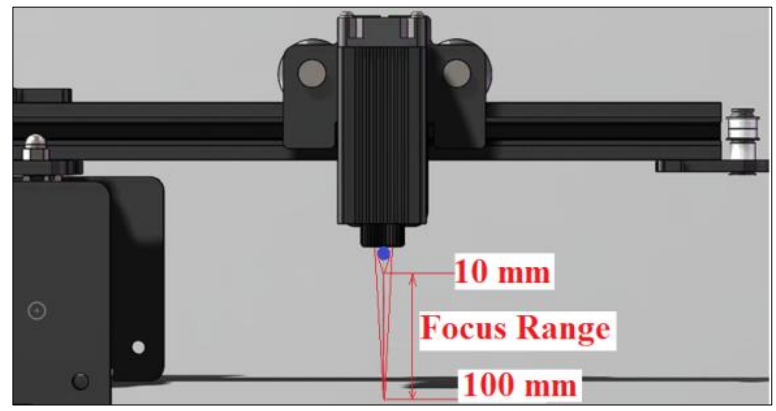

Figure 2. Adjustment of the laser beam focus

The proper adjustment implies the execution of a circular, focused spot and a minimum diameter on the area to be processed.

After setting out the pattern to be engraved or cut, the processing parameters shall be adjusted. They are shown in Figure 3. 


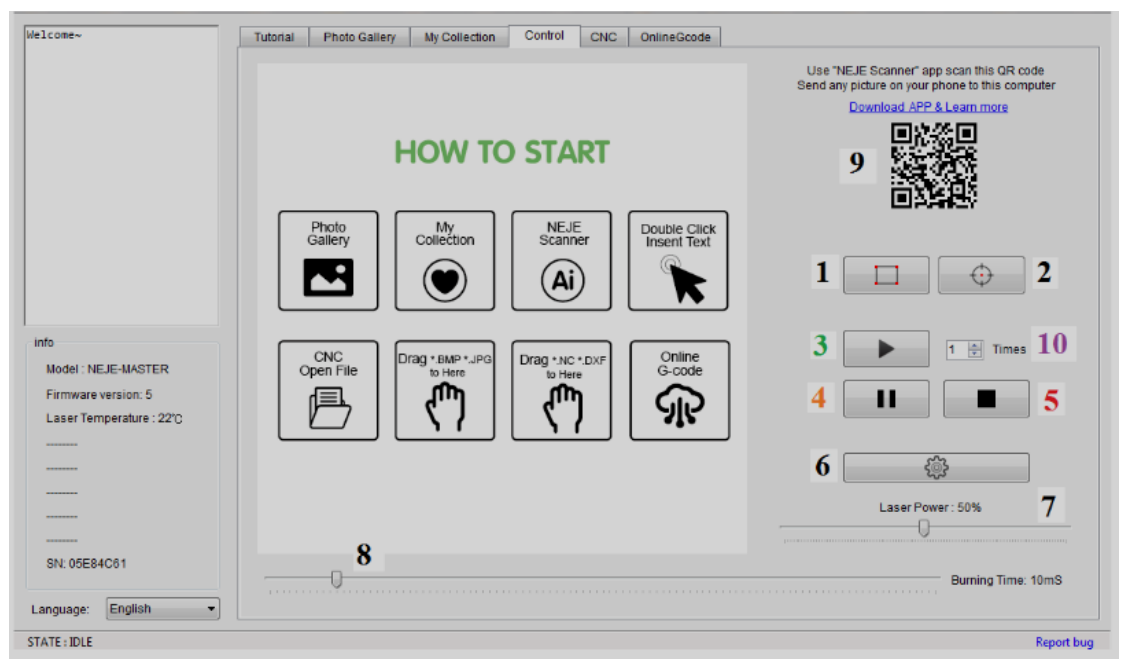

Figure 3. Adjustment

of the operating parameters

With the help of control "1", the perimeter where the processing is to take place shall be established. By operating control " 2 ", the center of the net field shall be visualized. The focus adjustment can be carried out here as in Figure 2. The command to start the processing shall be executed by activating button " 3 ". The interruption of processing shall be executed on " 4 " and the cancellation of processing from command "5". Other settings [1] shall be executed from button " 6 ". The maximum power of the laser used is $20 \mathrm{~W}$. Using command " 7 ", the percentage value of the power used can be established. The time required to "burn" with the help of the laser beam in one point, expressed in "[m]s", can be adjusted using command " 8 ". To download photos directly, code "9" shall be used. The number of passes of the laser beam on the same trajectory shall be adjusted using command " 10 ". This command is useful especially for cutting.

\section{Results and discussions}

The results of the plastic part laser processing depend on a number of factors which can be divided into two categories;

1-the factors related to the material to be processed;

2-the factors depending on the machine capacities and adjustments.

Among the factors that depend on the processed material we mention: its composition, its melting temperature, the quality of the semi-finished plate (color, polishing level, flatness), its ignition temperature, density and, if cut, the thickness of the semi-finished product etc.

In general, special materials are recommended for industrial engraving and photoengraving.

Among the factors that depend on the machine capacities and adjustments we mention: the maximum power of the laser beam, the adjusted processing power, the burning time, the number of passes, the speeds on the two axes, the focus quality, the clearance sizes in the feed systems on the "X" and "Y" axes, the existence of the cooling systems and, possibly, exhaust system if smoke occurs.

The machine used is a low-power machine, intended mainly for engraving and photoengraving operations. For certain low-thickness semi-finished products, it can also be used for cutting.

To execute engravings, two more frequent situations were selected: the engraving of certain drawings and texts (letters). The materials used are the usual materials resulting from the recycling of certain waste: old CD casings, folder covers, packing foam, waste resulted from plates used for the guides of machine tools [5], vinyl covers and waste resulted from hard plastic plates.

Table 1 shows several results obtained to engrave item "FLANGE". 


\section{Table 1}

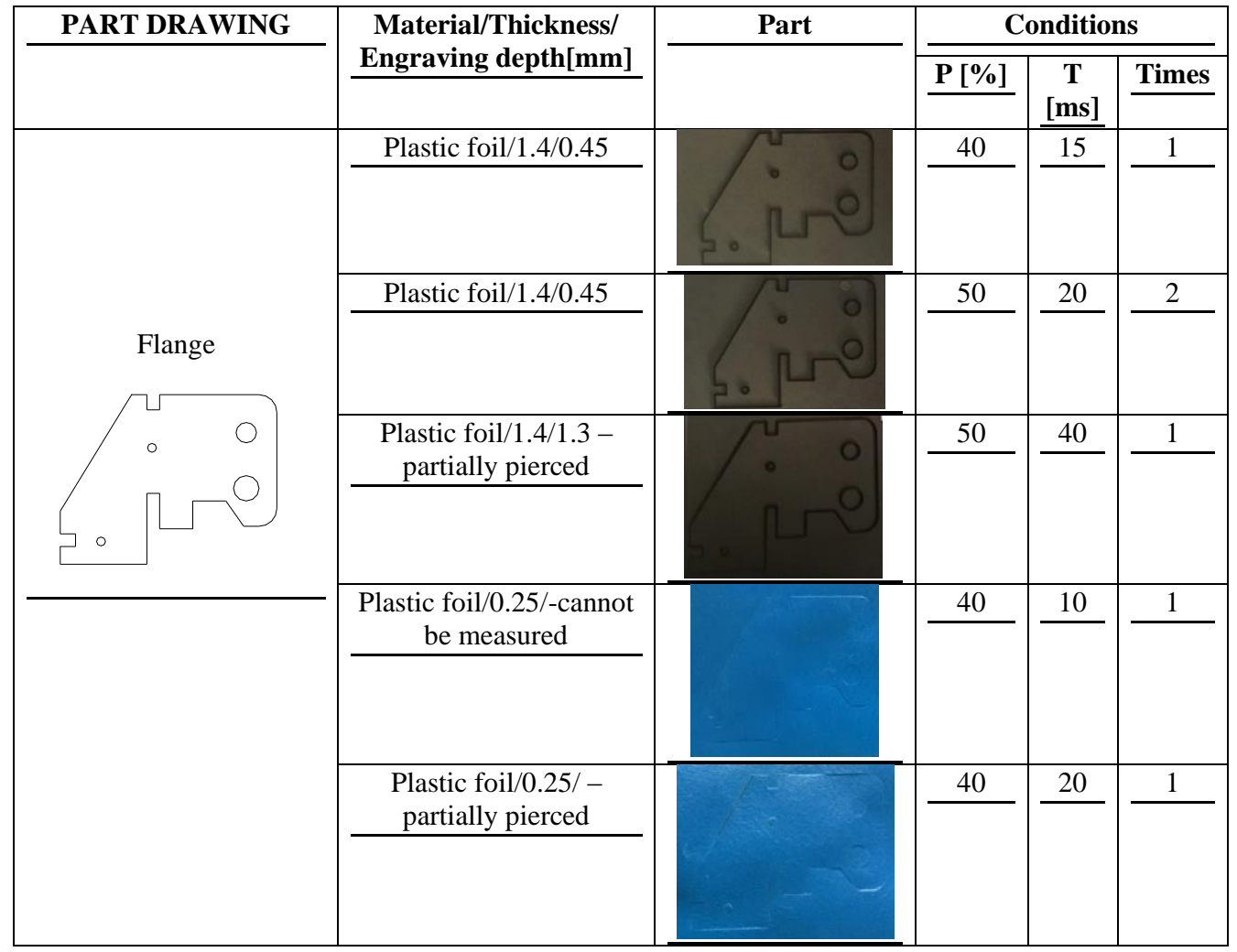

From Table 1 there results that the power output and the burning time directly influence the engraving depth. On the same focus, the thickness of the engraving lines results from the burning time. If there is a second pass, the engraving depth shall not double for the materials used. This can be explained by the fact that the focus adjustment on the first pass is not optimum for the second one any longer. Ideally, the laser should be close to an increment equal to the engraving depth on the first pass.

Another engraved area represents a COGWHEEL [3], shown in Table 2. This time, the following materials were used: thermoplastic material [5], hard plastic and foam.

Table 2

\begin{tabular}{|c|c|c|c|c|c|}
\hline \multirow[t]{2}{*}{ PART DRAWING } & \multirow{2}{*}{$\begin{array}{c}\text { Material/Thickness/ } \\
\text { Engraving depth[mm] }\end{array}$} & \multirow[t]{2}{*}{ Part } & \multicolumn{3}{|c|}{ Conditions } \\
\hline & & & $\mathrm{P}[\%]$ & $\begin{array}{c}\mathrm{T} \\
{[\mathrm{ms}]}\end{array}$ & Times \\
\hline \multirow{3}{*}{ COGWHEEL } & $\begin{array}{c}\text { Thermoplastic material } \\
\text { WHITE/2.3/0 } \\
\end{array}$ & & 55 & 30 & 1 \\
\hline & $\begin{array}{c}\text { Thermoplastic material } \\
\text { BLACK/2.3/ 0.1 } \\
\end{array}$ & & 55 & 30 & 1 \\
\hline & $\begin{array}{l}\text { The copper plate } \\
\text { covered in synthetic } \\
\text { resin/1/ cannot be } \\
\text { measured }\end{array}$ & & 30 & 10 & 1 \\
\hline
\end{tabular}




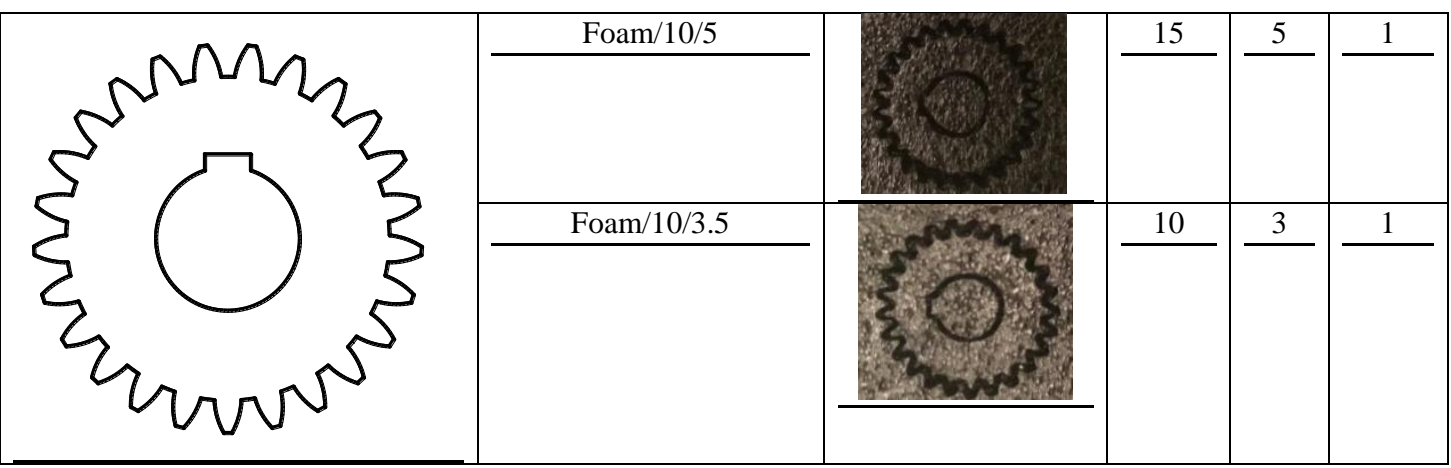

The structure and the colour of the material decisively influence the engraving possibilities. Thus, for the white thermoplastic material, intended for working under difficult conditions [2,3,5], it turns out that the engraving becomes impossible. If the material is prepared by black painting, a superficial engraving is obtained, without practical applicability. The engraving carried out on a copper plate covered with a thin layer of synthetic resin allows visible printings, obtained up to the metallic surface. Even if a lower power and 3-5 ms burning times are used, the foam is engraved in depth. This material tends to ignite and, due to its spongy structure, an irregular contour is obtained.

Other engraved areas are presented in Table 3.

Table 3

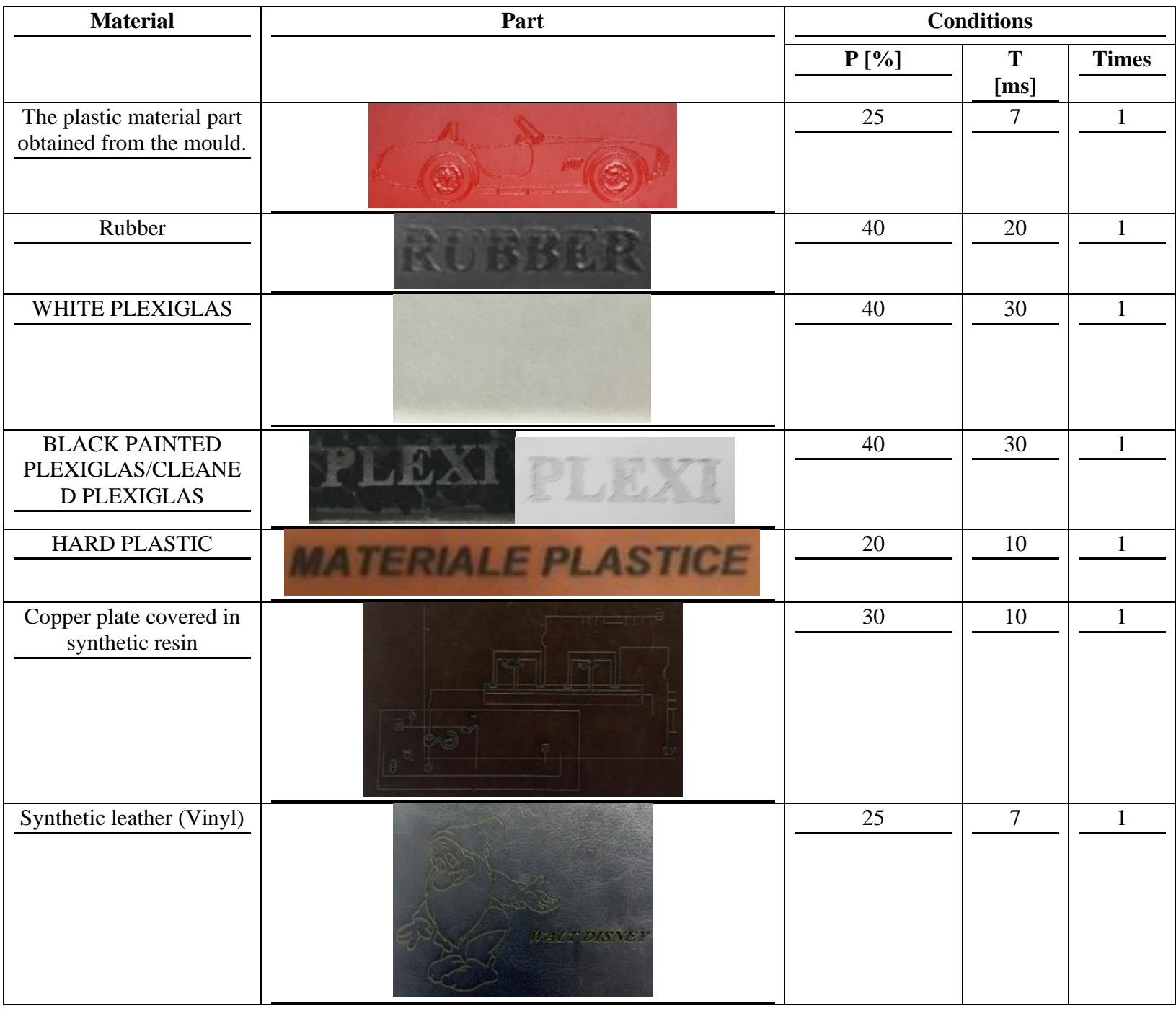


In this case, the printing of certain symbols or letters was aimed at. As far as the molded plastic part is concerned, due to the lack of parallelism of the area to be engraved with the placement area, we may notice that the engraving depth is not constant. Such lack of parallelism does not allow the same focus on the entire area. Due to its composition and colour, the rubber part was visibly engraved on a depth of $\sim 2.5 \mathrm{~mm}$. The transparent and glossy Plexiglas reflects the laser beam and thus cannot be engraved. If superficially covered, engraving is possible and remains visible after the paint is removed. Visible and persistent engraving can be executed on hard plastic plates or on plates covered in synthetic resins. The synthetic leather used in various fields can be easily engraved, thus obtaining customized images. Photoengraving requires that the images should be uploaded and centered. Photoengraving is the procedure that helps the execution of surface engraving based on good contrast black-and-white images. The result of image laser engraving shall always be a light-abstracted version of such image. The machine program, as we will see, also allows to upload color photos.

The quality and appearance of the engraving depend on both the model image resolution and contrast and on the behavior of the support material.

The best photoengraving can be achieved on wood and cellulosic materials, as well as on a series of specially-designed plastics.

Taking into account that the machine used is not intended for industrial use, the authors also used it to engrave common materials.

After uploading the photo (jpg format), one can select to save it in BLACK/WHITE format. The machine program offers several photoengraving options [7], as in Figure 4.

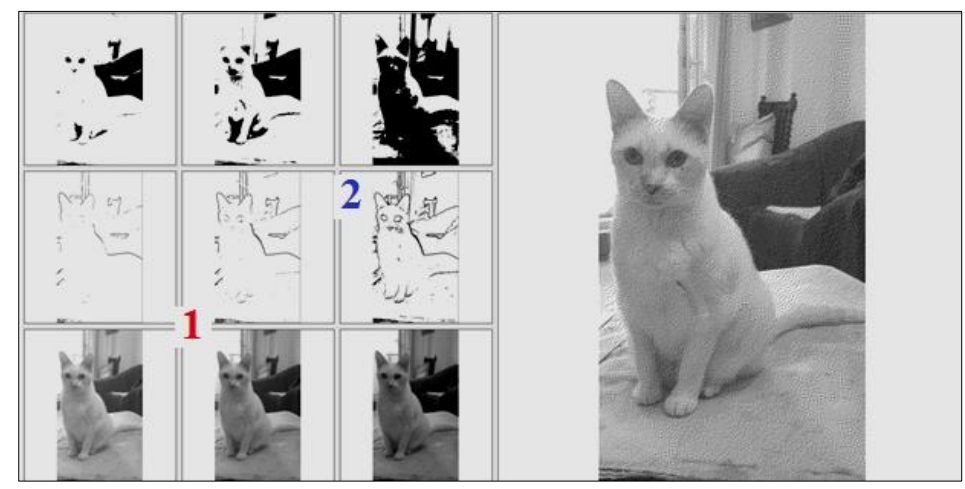

Figure 4. Photoengraving options

For the photo on the right, nine photoengraving options are available. The selected versions are "1" and " 2 " and they are shown in Table 4.

Table 4

\begin{tabular}{|c|c|c|c|c|c|}
\hline \multirow{2}{*}{$\begin{array}{l}\text { ORIGINAL } \\
\text { PHOTO } \\
\end{array}$} & \multirow{2}{*}{$\begin{array}{c}\text { BLACK-WHITE } \\
\text { TRANSPOSITION } \\
\end{array}$} & \multirow[t]{2}{*}{ Selected version } & \multirow[t]{2}{*}{ Photoengraving } & \multicolumn{2}{|c|}{ Conditions } \\
\hline & & & & $\begin{array}{c}\mathbf{P} \\
{[\%]}\end{array}$ & $\begin{array}{c}\mathbf{T} \\
{[\mathrm{ms}]}\end{array}$ \\
\hline & & & & 25 & 4 \\
\hline & & & Plastic foll $1.4 \mathrm{~mm}$ & 30 & 10 \\
\hline & & 1 & & & \\
\hline & & & Synthetic leather (Vinyl) & & \\
\hline
\end{tabular}




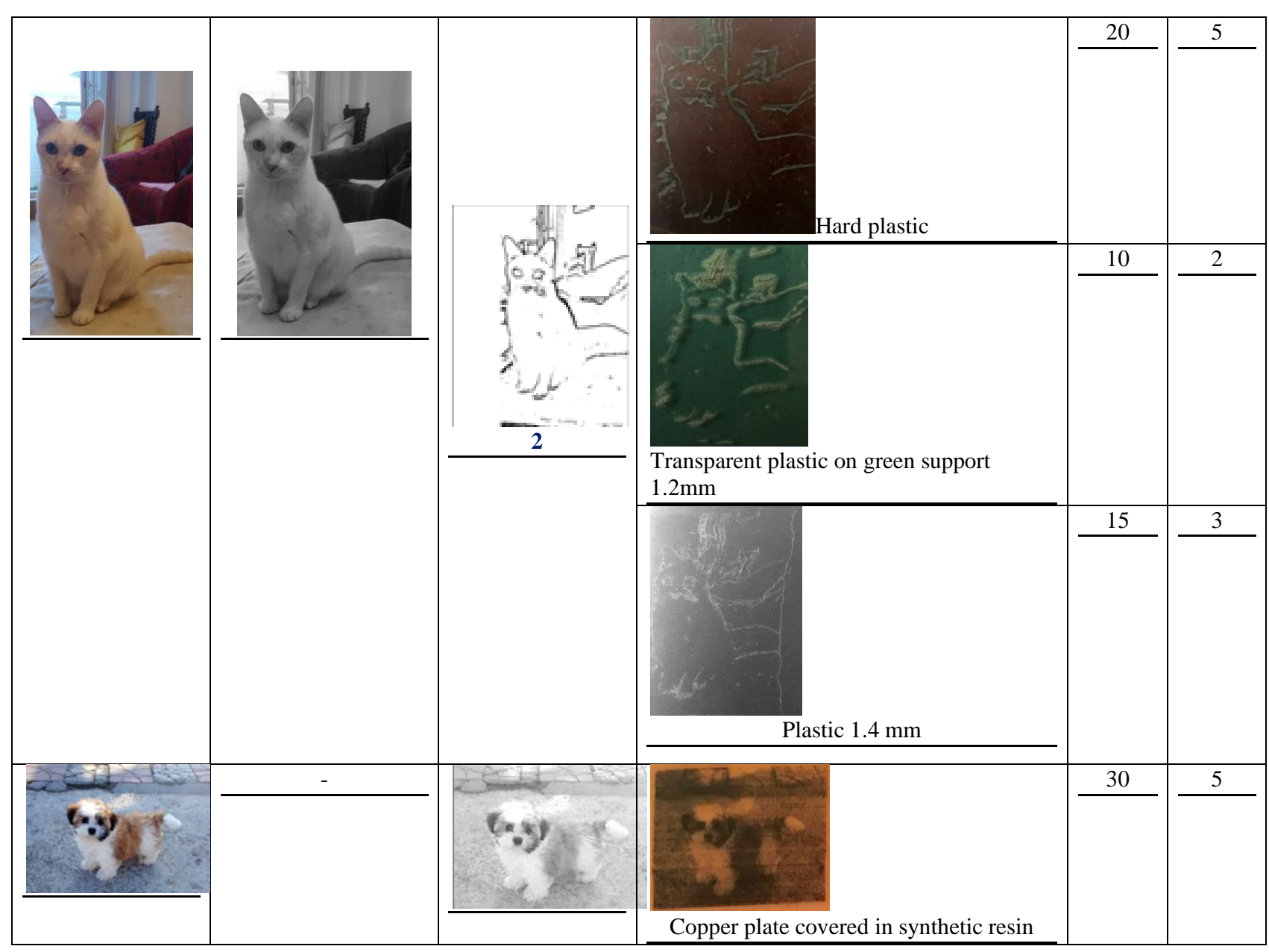

The last line in Table 4 shows the photoengraving outcome straight from the color photo. The table above shows that it is recommended to switch from the color format to the BLACK/WHITE one and that high-fidelity versions should not be selected in order to obtain the best results. The higher the fidelity, the higher the risk to burn the material around the spot. At the same time, the processing times increase dramatically in such cases. The photoengraving carried out on synthetic leather or on the areas covered in resin or in a thin layer of plastic is of good quality. In such cases, special attention shall be paid to adjustments. It is recommended that for adjustment, a new adjustment should be carried out for each change of material (quality, color, thickness and gloss) $[9,10]$.

Taking into account the maximum $20 \mathrm{~W}$ power, the cutting options of this machine are limited. However, cutting was achieved after one single pass, as noticed in Table 5.

Table 5

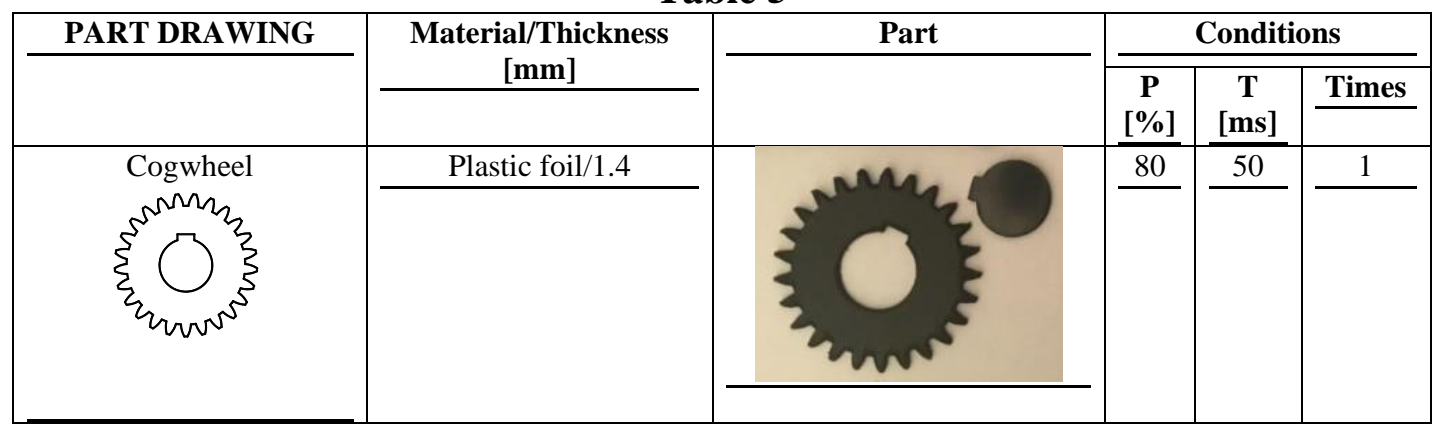




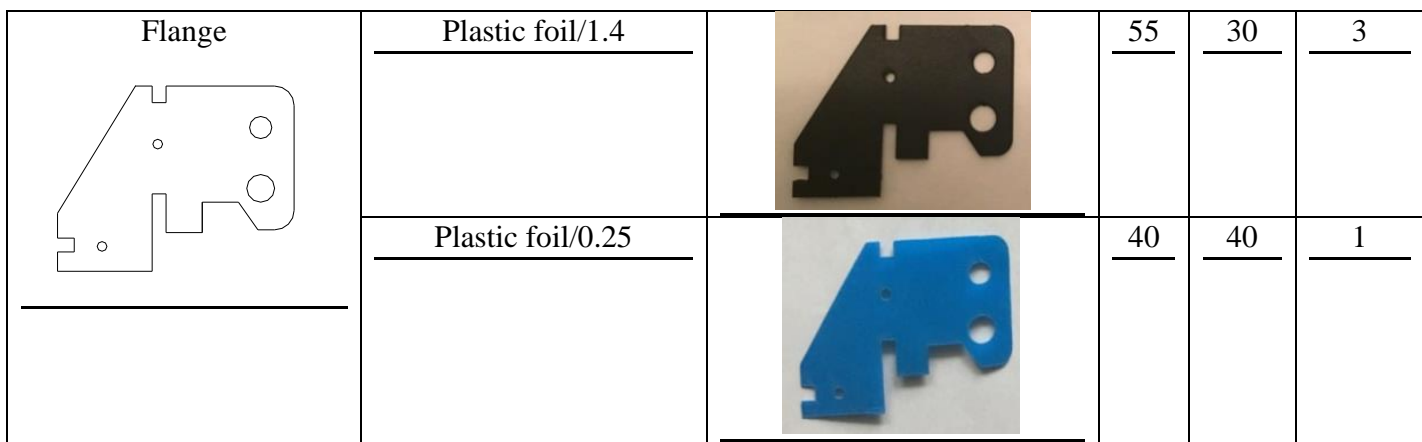

The cogwheel was obtained from one single pass but we could notice the melting and distortion of the part on the involute area of the teeth. If the power and the times were reduced for the $1.4 \mathrm{~mm}$-thick material, a perfect cut was obtained after three passes.

Figure 5 shows the cutting of the FLANGE item. After each pass, there is the possibility to modify power and burning time

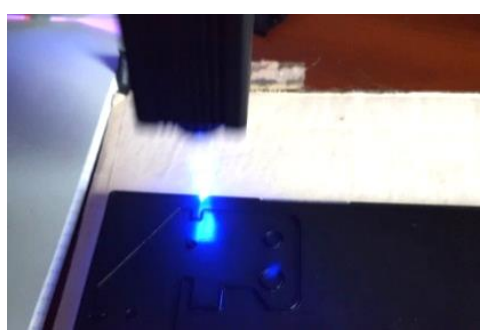

Figure 5. The cutting of the FLANGE item

If the material is thin $(0.25 \mathrm{~mm})$, the cutting is achieved from the first pass.

In case of several passes, it would be necessary that, after each one, the laser spot should be lowered by a ratio equal to the previously-executed cutting depth. In such case, another vertical driveline is required therefore the " $Z$ " axis [2-4].

If the engraving and photoengraving areas need to be cylindrical, the movement of the "Y" axis needs to be taken over and turned into the rotation of the semi-finished product around the " $\mathrm{X}$ " axis and so, for each pass on the " $\mathrm{X}$ " axis, the semi-finished product should rotate at an angle corresponding to it and to the cylinder radius $[6,8]$.

\section{Conclusions}

Low-power laser machines (max. 20W) are recommended for occasional use, by small companies, for engraving and printing. They are not recommended for industrial use.

Due to the processing accuracy, they allow high-precision processing on small areas. From this point of view, they are substantially superior to metal-cutting machines and to $3 \mathrm{~d}$ printers.

From the point of view of the processing speed and accuracy, the laser-processing machines are significantly superior to the classic ones which chip metal or even to 3D printers.

To obtain high-quality processing, it is recommended to execute sample testing from such material beforehand, thus establishing the power, time and the number of passes required.

Engraving is the operation that can achieve the best results.

As far as cutting is concerned, it can be executed at the limit, on certain materials, usually several passes being required.

During processing, certain materials give off smoke. The smoke suction is recommended, not to reduce the processing power. 
Another advantage of such machines is that they do not eliminate flakes and the quality of the surfaces resulted from cutting is very good.

The best results are obtained if the machine is fixed, the plan of the "X" and "Y" axes being parallel to the horizontal plan. For assembly, it is recommended the use of a perfectly-horizontal fixed table and a levelling box. Due to the high working speeds, especially on the "X" axis, it is recommended to attach the machine on the fixed table.

\section{References}

1. *** wiki.nejetool.com

2. JOSHI, P. H., Machine tools handbook design and operation, New Delhi, Tata McGraw-Hill, 2007.

3. PEROVIC, B., Handdbuch Werkzeug-maschinen, Auslegung und Konstruktion, Munchen, Carl Hanser-Verlag, 2006.

4. PRODAN, D., Masini-Unelte grele Sisteme Mecanice si Hidraulice, Editura Printech, Cod CNCSIS 54, Bucharest, ISBN 978-606-521-474-3, 2010, p. 227.

5. PRODAN, D., BUCURESTEANU, A., MOTOMANCEA, A., BALAN, E., Remanufacturing of Heavy Duty Machine Tools Guideways Plating with Plastic Materials, Mater. Plast., 53(4), 2016, 599

6.VLĂSCEANU, D., BACIU, F., POPESCU, D., HADĂR, A., MARINESCU, R., Development and 3D Printing of an ABS Ergonomic Handle for Medical Use A case study", Mater. Plast., 55(4), 2018, 630-633

7. POPESCU, D., ILIE, C., LĂPTOIU, D., HADĂR, A., BARBUR, R., Web-based Collaborative Platform for Personalized Orthopaedic Application, Studies in Informatics and Control, 25(4), December 2016, pp. 517-526

8. BIRD, J., (2012-08-08). Exploring the 3D printing opportunity. The Financial Times. Retrieved 201208-30

9.GIBSON, I., ROSEN, D. W., STUCKER, B., Additive Manufacturing Technologies - Rapid Prototyping to Direct Digital Manufacturing, Publisher: Springer, New York, 2010

10.WOERN, A.L., PEARCE, J.M., Distributed Manufacturing of Flexible Products: Technical Feasibility and Economic Viability, Technologies 2017, 5(4), 71; doi:10.3390/technologies5040071

Manuscript received: 4.04 .2020 